\title{
Effect of Nutrients on Diatom Growth: A Review
}

\author{
Tapas Giri', Umesh Goutam¹, Aditi Arya ${ }^{2}$ and Shristy Gautam ${ }^{1, *}$ \\ ${ }^{I}$ Department of Molecular Biology and Genetic Engineering, School of Bioengineering and Biosciences, \\ Lovely Professional University, Punjab 144411, India \\ ${ }^{2}$ Department of Biotechnology, Deenbandhu Chhotu Ram University of Science and Technology, \\ Haryana 131039, India
}

("Corresponding author's e-mail: shristy.g@gmail.com)

Received: 31 July 2020, Revised: 1 June 2021, Accepted: 30 June 2021

\begin{abstract}
Diatoms are one of the unicellular algae with a rare presence of unaltered, durable, transparent and species-specific silica frustules that persist even after cell death in the deposits of water bodies. Diatom has high capacity for absorption of metals for maintaining the water quality and high rate of multiplication. These characters promoted the use of this microbial biomass for effluent detoxification. These diatoms can also solve metal toxicity problems in aquatic ecosystems in the water polluted environment. In the present review, the focus is on several nutrients (nitrogen, phosphorus, iron and silica) that are essential for the growth of diatoms at very low concentrations, but most of them are toxic at high concentrations. It also shows the relationship between heavy metal stress and lipid body induction which may be a valuable indicator for the evaluation of heavy metal contamination of fluvial ecosystems.
\end{abstract}

Keywords: Biomonitoring, Deformity, Diatoms, Lipid bodies, Nitrogen, Silica

\section{Introduction}

Diatoms are unique, silica-containing microscopic algae with distinct geometric forms. They are eukaryotic, unicellular, and photosynthetic in nature. They are $5 \mu \mathrm{m}-0.5 \mathrm{~mm}$ in their thickness. They can be found in every waterbody. They are either planktonic, or benthic in nature (Figure 1). Diatoms are typically non-motile but some benthic diatoms have a special raphe to secrete mucilage to fasten or float along a surface. These often form biofilms, i.e. the cells of microorganisms closely bound to them [1]. Biofilms with extracellular fluids around it are also formed on a solid surface. Diatoms are fresh-andmarine photosynthetic species. They are rich sources of high-value molecules (HMVs) such as eicosapentaenoic acid, chrysolaminarin, docosahexaenoic acid and fucoxanthin (Fx), which have extensive uses in the pharmaceutical, chemical, and medical sectors. Apart from HVM, silica nanoparticles are used in nano-biotechnologies, for drug delivery, for nano-biosensors and for micro- and nano-fluidics specific control. It is estimated to be around 200,000 different species [2] and Scientists continue to discover new species every year. They play a vital role as indicator in climate change and forensic analysis. These are also the primary producer of oil in the world responsible for fixing $25 \%$ of $\mathrm{CO}_{2}$ and $30 \%$ of crude oil diatoms [3].

They have the capacity to survive in diverse conditions, including high temperature. It has also been reported that when diatoms are put under stressed conditions such as low nutrients, high temperature, low silica, high or low light, etc. the concentration of their oil increased. As a result, lipid metabolism can range from intracellular plasma membrane synthesis to lipid storage [4]. Genetic transformation of diatoms or selective breeding can also be used to increase the oil production in diatoms under various stress conditions [5]. It was reviewed from the previous literature that 1 diatom Diadesmis confervacea produced maximum oil among other diatoms whereas all other diatoms produced oil, but the visible oil content was very low [6]. Diatoms have high lipid content and naturally oozing property which would eliminate the expensive step in energy production of extracting oil out of the other diatoms.

The population of diatoms has undergone an irregular cell growth, reduced size and teratological changes mainly because of the impacts on industrial waste, mining, soil sedimentation, solar radiation, drought, temperature rises and water flow and speed changes [7]. Diatoms morphological anomalies were examined extensively, but typically under heavy metal stress, under different forms of environmental anthropogenic disruption. Diatom deformity is not widely used to assess the consistency of aquatic 
environments, given its global recognition. It is primarily because of the low number of deformities which complicate the research process and lead to the fact that the frequency of deformities and heavy metals is statistically poorly assessed [8]. For example, the statistical weakness between the concentration of metals and diatom deformities was detected in Quebec sedimentary samples in Canada [8].
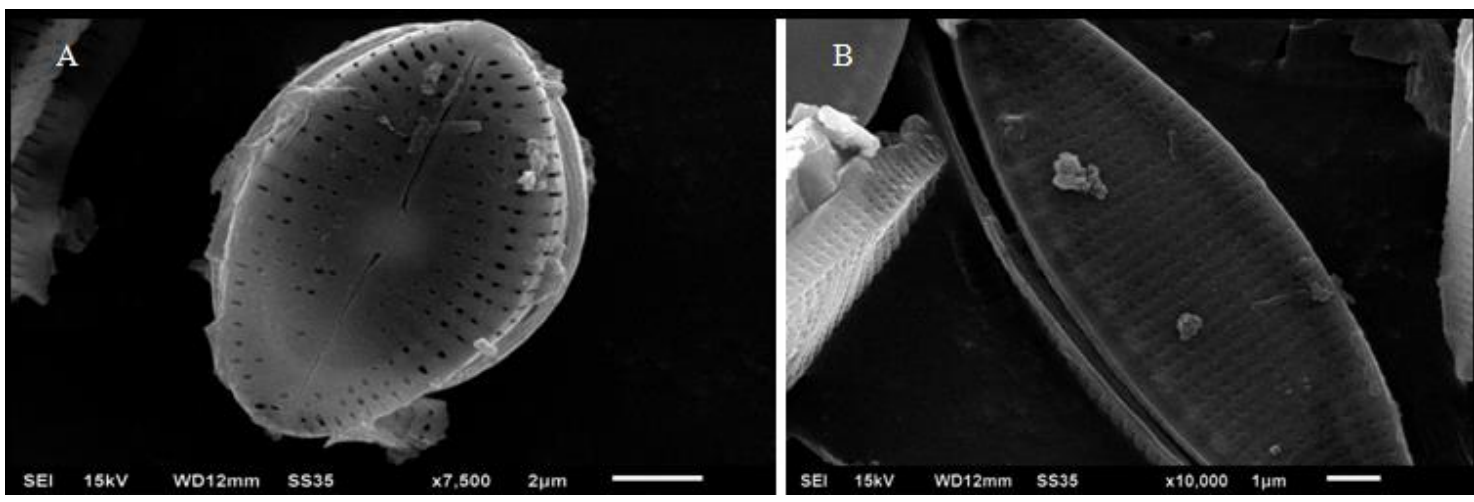

Figure 1 Scanning electron micrographs of different diatom species. A) Diadesmis confervacea and B) Nitzschia palea.

\section{The unique silica cell wall}

Diatom populations are a wide range of life forms and consist of a special silica cell wall, called "frustule". Few living organisms that make use of silica. Since silica is similar in structure to glass in these frustules, the diatoms are known as "green growth in glass houses." The frustule comprises of 2 valves, i.e. 2 valves, which are overlapping. One frustule is a larger valve-epivalve and a smaller valvehypovalve that keeps all valves together. The epivalve fits like a box lid over the hypo valve. Frustules are of a different nature and are formed with pores, spines and height. Taxonomists order diatoms into 2 noteworthy gatherings based on symmetry; 1) Centrics- round; outspread symmetry, and 2) Pennatesstretch; reciprocal symmetry. Diatom scientific categorization depends upon morphological features like shape, size and instances of frustules [1].

Diatoms use silicic acid present in the nature for silica formation in frustules. For this, they have specific structures called silica deposition vesicles (SDVs) which polymerize silicic acid. Two types of SDVs, i.e., valve and girdle band SDVs; work at different stages of the cell cycle. The nucleus of each daughter cell draws closer to the microtubule centre (cytokinesis). The microtubule centre lies below the plasma membrane where the hypovalve is eventually synthesized. The valve SDV involved with valve formation aligns between the microtubule centre and the plasma membrane forming a region called the pattern centre. The SDV then synthesizes a hypovalve in an organized fashion, using silica and biomolecules, by gradual expansion [1].

The hypovalve then fuses with the plasma membrane offering ascend to 2 daughter cells by exocytosis. Since the siliceous cell walls cannot expand, the daughter cells are smaller than the parent and undergo cell growth. The distance between the rigid valves needs to be increased before mitotic division. Therefore, several succeeding lateral girdle bands are formed in girdle band SDVs and are released (exocytosis) synchronously with cell growth during interphase [9]. As this counteracts hole arrangement in the frustule, cell components never get directly exposed to the environment.

\section{Asexual and sexual life cycle of diatoms}

Diatoms have a diplontic life cycle that ensures that the diploid structure dominant the haploid structure. Diatoms typically have vegetative replication (asexual) (Figure 2). The cells are formed by mitosis inside the parent cell during vegetative development. Every parent act as an epivalve in the hypovalve. Therefore, every new cell has an epivalve and hypovalve. This means that 1 daughter cell of the parent maintains the same size, while the other portion of the hypovalve is slightly smaller than that of the parent. Consequently, normal cell estimates decrease with progressive divisions in a population for a specific species. As a result of cell estimate (especially, length) decrease, the relative cell measurements change. The total range of size and shape differences in the population is referred to as the size diminution series. This phenomenon was immediately described by Macdonald and Pfitzer [10,11], which 
was also called the theory of MacDonald - Pfitzer. This unusual phenomenon also has an effect on the performance of mitotic division [12].

The reduction in size only happens before the cell is able to reach a minimum of acceptable size. Diatoms recover the extreme size of an auxospore production also called perizonium in a particular cell. The diatom lifecycle is related to meiosis and sexual reproduction. After mixing male and female gametes the auxospore is formed. The basic form of each diatom species is formed during auxospore expansion. Auxospore does not have a rigid cell wall but a perizonia (silica bands) [9]. It helps the cell to expand to its highest size and develop an imposing form. In unfavorable conditions, such as nutritional shortage and extremely low temperatures, diatoms often form resting cells. These are not physiologically the same as vegetative cells, but are only formed by cell division, whereas increasing cell volume during the interphase requires a step-by-step synthesis of bands, so that there are no gaps between the epitheca and the hypotheca within the cell wall. As vegetative growth continues, the average cell size for a diatom population is gradually declining (the MacDonald-Pfizer rule) [13]. Ultimately, this size reduction will lead to a viability of too small cells and to the death of the population of diatoms. The only way to escape this destiny is through sexual reproduction. In this cycle, meiotic cell divisions occur and gametes discard their cell walls [14]. The specialized zygote (auxospore) was formed immediately following gamete-fusion with a covering organic wall and, for a comparatively short period (hours to several days), its volume grew tremendously. Valves with a siliceous pattern were formed during the first division of auxospore only during the first period (Figure 2).

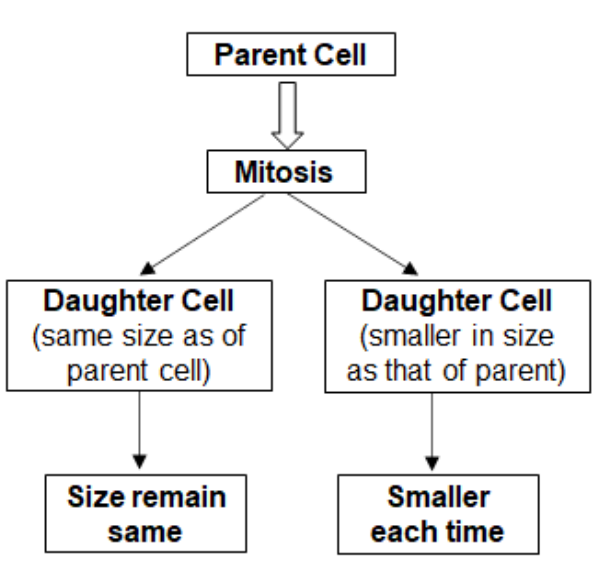

(a) asexual reproduction in diatoms

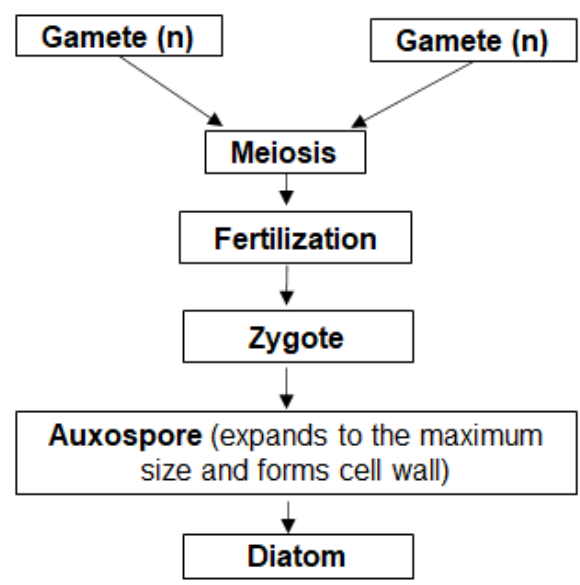

(b) sexual reproduction in diatoms

Figure 2 Diagrammatic representation of life cycle of diatoms (a) asexual reproduction in diatoms and (b) sexual reproduction in diatoms.

\section{Effect of various heavy metal stress on diatom}

Diatom development relies upon various environmental parameters, including the presence in metals. At the time when there are sufficient small nutrients, cells are ready and grow at their highest rate of growth. The optimum metal quantity is typically deformed in the cell membrane and the cells experience devoid/excess of the heavy metal element (HM) in the soil. Metabolic processes lead to a dysfunction which reduces development and ultimately can lead to cell mortality in abundance [15]. With respect to other phytoplankton species, they require lesser amounts of ions, such as $\mathrm{Cu}, \mathrm{Ca}^{2+}, \mathrm{Mn}, \mathrm{K}^{+}, \mathrm{Fe}, \mathrm{Mo}^{2+}$, $\mathrm{Mg}^{2+}, \mathrm{Zn}^{2}, \mathrm{Ni}^{2+}$ are vital for growth and cell physiology. Apart from the essential micronutrients, there is no physiological role observed in excessive ions, such as $\mathrm{Co}^{2+}, \mathrm{Na}^{+}, \mathrm{Cd}^{2+}$ and $\mathrm{Hg}^{2+}[15]$.

\section{Role of metal required for the growth of diatoms}

Diatoms cultivated under nutrient limitation show considerable variation in biochemical composition such as lipids, proteins, carbohydrates based on nutrient limitations and degree of limitations (growth rate as $\mu_{\max }$ percentage) [16] Some of the changes are specific only to a certain nutrient limitation (e.g. $\mathrm{N}$ limits and content of protein), while some appear to be indicators of stress or low growth generally (e.g. increased triglycerides and carbohydrates). Many studies have extensively documented that algal growth 
requires nitrogen, phosphorus, iron and silica [17,18]. These nutrients are assimilated as biochemical components in algal cells for formation of cell walls [19]. It was observed that under nutrient limitation, the cell size of diatom Stephanodiscus minutulus was declined significantly and N-limited cells are significantly smaller than Si or P limit cells [16]. The cell size had a positive correlation with protein and a negative correlation with carbohydrates, making the protein:carbohydrate ratio the best cell size predictor. The essential inorganic nutrients needed for diatom growth are nitrogen $(\mathrm{N})$ and silicon $(\mathrm{Si})$. Although variations exist, a relative equilibrium of $\mathrm{N}: \mathrm{Si}$ in the biomass is found for many marine diatoms. Therefore, Si limits of diatom growth may be due to increased inorganic N:Si ratio. The change between $\mathrm{N}$ and $\mathrm{Si}$ is likely to affect both the quantity such as cell, biomass numbers and the quality such as composition of biomass of the diatom population [20]. The needs of copper $(\mathrm{Cu})$ and zinc $(\mathrm{Zn})$, at least for higher plants and green algae, are firmly known because both elements play an important role in protein structure and metabolism. These 2 elements actually form the tightest ligand complexes. Moreover, $\mathrm{Zn}$ plays a leading role in electrophile enzyme catalysis, and $\mathrm{Cu}$ is a broker for redox transformations. Despite cu or Zn-superoxide dismutase (SOD) in eukaryotic algae being alleged absent, the $\mathrm{Cu}$ or $\mathrm{Zn}-\mathrm{SOD}$ coding gene was found through genomic analysis. $\mathrm{Cu}$ or $\mathrm{Zn}$-SOD is the most abundant Zn-containing type of carbonic-anhydrase (CA) enzyme. CA assigns a metallolyases group to catalyse water-based reverse transformation between $\mathrm{HCO}_{3}$ - and $\mathrm{CO}$. $\mathrm{Zn}$ is also a cofactor in many forms of $\mathrm{Zn}$ finger transcription and affects its stability [21]. Thalassiosira oceanica Hasle, for example, uses plastocyanin for oceanic diatoms, but instead uses cytochrome c-6 for coastal plants, such as Thalassiosira pseudonana Hasle and Heimdal and Phaeodactylum tricornutum Bohlin. Accordingly, copper is less demanding for former species. Copper proteins are also active in the mitochondrial respiratory chain, the metabolism of the cell wall and metal homeostasis. Cadmium $(\mathrm{Cd})$ is a soft metal that has a good peroxidation potential for sulfhydryl-ligands affinities. Therefore, $\mathrm{Cd}$ is generally regarded as a toxic element with the exception of oceanic diatoms, in which a special carbonic-anhydrase shape may be substituted by the $\mathrm{Zn}$ atom. The diatom phenomenon of sodium is noteworthy because in the absence of $\mathrm{Na}$, cell division of multiple marine diatoms is avoided [22]. Over-abundant metals are primarily influenced by changes in the form and/or the size of frustule. If the frustules constitute a highlevel metal ion-sorbent, the addition of Fe has significantly increased the growth of these populations by means of experiments with typically natural oceanic plankton community in the Southern Ocean [23]. On the other hand, just marginally improved phytoplankton growth by adding $\mathrm{Mn}$, Co or Zn alone. Iron (Fe) did not result in a substantially higher growth scores with 1 or more of the 3 trace metals, compared with $\mathrm{Fe}$ alone. Such findings both within and outside show that the co-limitation of metals other than Fe is typically not occurring [24].

Sodium $\left(\mathrm{Na}^{+}\right)$has pleiotropic effect and in over-abundance, it is a key component in the structuring of diatom communities and primarily responsible for cell size reduction, development and physiological mechanisms. On the other hand, in rivers freshwater diatoms can survive to demonstrate their halotolerance. The effects of sodium on diatom growth and development are focused on the control of other nutrients such as potassium and silica, which is dependent on the carrier. Nitzschia alba Lewin and Lewin marine diatom is Na-dependent, comprising $1 \mathrm{Na}$-dependent ATPase and $1 \mathrm{Na}$, K-dependent ATPase. This also increases the rate of silicate absorption, necessary for frustule formation, when the extracellular concentration of $\mathrm{Na}$ increases [25]. The abundance of $\mathrm{Cu}$ and $\mathrm{Zn}$ has affected both the metabolism of cells and plastids; it has reduced the production of diatom biomass. In the hypothesis, the decrease in growth is generally interpreted as a decrease in photosynthesis, because the production of biomass requires $\mathrm{CO}_{2}$ fixation through a photosynthesis process. Nonetheless, species comparisons have shown that biomass changes are not necessarily related to a decline in the photosynthesis or the quality of photosynthesized pigments [26].

$\mathrm{Cd}$ a versatile variable component capable of influencing gene expression, electron transfer chains and diatom group structure. The expression of the subunit of cytochrome c oxidase and the subunit 5 of $\mathrm{NADH}$ is decreased in the presence of $\mathrm{Cd}$, which has an effect on the mitochondrial metabolism. Cd can inhibit electron transfer in mitochondria after entering the cell, leading to radical oxygen species (ROS) formation. Furthermore, $\mathrm{Cd}$ can transfer $\mathrm{Zn}$ and $\mathrm{Cu}$ from metal enzymes. The replacement of $\mathrm{Zn}$ with $\mathrm{Cd}$ in the CA active area causes the net carbon fixing rate to drop sharply as a response to rapidly increased (hours) salinity. $\mathrm{Cd}$ also slows the xanthophyll reaction down, preventing diatoms from responding efficiently to subsequent light stress. The adequacy of $\mathrm{Cd}$ effects at the genetic, biochemical and cellular levels describes the various thresholds for toxicity. It is not surprising, according to this data, that $\mathrm{Cd}$ is changing the diatom community structure [27]. 


\section{Response of diatoms on nitrogen}

Nitrogen (N) is a significant component of cell macromolecules such as lipids and chlorophyll, essential to virtually all organisms. In response to biological and physical processes, nitrogen availability varies considerably in the marines, in the temporal scales. Nitrogen $(\mathrm{N})$ availability has a strong influence on algal growth [28]. The relative availability change of $\mathrm{N}$ may impact on the abundance of different diatom species [20]. Diatoms are directly connected to their carbon metabolism by nitrogen uptake and assimilation. Nitrogen assimilation requires ATP and photolytically derived reductants and TCA-derived carbon skeletons $[29,30]$. When the growth of diatoms is reduced by nitrate availabilities, the levels of protein and cellular nitrogen levels are decreasing and the ratio of carbon to nitrogen are increasing [31], and the storage of carbon-rich compounds like lipids is increasing [30,32,33].

The effect of nitrogen starvation on photosynthesis pigments has been studied. A decline in chlorophyll pigments leads to cell chlorosis and reduces photosynthesis capability, thereby negatively affecting cell growth, carbon fixation and energy conversion [29]. Due to nitrogen deficiency, diatoms reprogram multiple metabolic pathways in certain diatom organisms, for example, primary carbon metabolism decreased and lipid content accumulated [34]. A 2-dimensional proteomic strategy for gel electrophoreses (2-DE) was studied at the beginning of nitrogen starvation in the nitrogen replete cells [35]. Seventy-five altered proteins were identified and they were involved in the metabolism of oxygen, amino acids, proteins, carbohydrates, photosynthesis and chlorophyll biosynthesis. These results indicate that Thalassiosira pseudonana nitrogen starvation varies significantly from the central carbon metabolism response of the other eukaryotic photoautotrophs and is similar to cyanobacterial reactions. Another proteomic test systematically examined molecular changes in Phaeodactylum tricornutum to neutral accumulation of lipids during deprivation of nitrogen. The results showed that nitrogen starvation contributed to a more regulated genetic environment for nitrogen and fatty-acid biosynthesis, followed by less regulated genes involved in photosynthesis and lipid catabolism, leading to a change from a carbon flux to a lipid accumulation in the diatom metabolic network [30].

\section{Response of phosphorus on diatoms}

The supply of phosphorus is recognized as a critical factor for phytoplankton growth. Phosphorus levels are lower in many marine ecosystems and growing evidence indicates that phosphorus initially limits marine production. Diatom physiological responses to the deduction of phosphorus are least understood in any situation. The related deep sequencing patterns for transcribed marks and proteomic studies [36]. Therefore, the reaction of the diatom to the deduction of phosphorus comprised a complex and multi-faceted transcriptome remodelling, usually related to the expressed mRNA reaction. The cell phosphorus assignment patterns, enzyme activity as well as lipid composition consistent with transcriptome and proteomic trends were also clearly physiologically changed [37]. The transcriptome and proteome relationship revealed $T$. pseudonana. The response of $T$. pseudonana to phosphorus deficiency has been novel and reaffinated and includes the following several biochemical strategies: 1) the cellular shift allocation for phosphorus; 2) the increase in phosphorus transport; 3) usage of dissolved organic phosphorus; 4) Cell surface reconstruction and 5) glycolysis and translation control. Therefore, a major protein-level induction from diesterase indicates the importance of this enzyme in phosphorusdeficient Thalassiosira pseudonana cells with new insights into photoplankton stress reactions [37]. The nitrogen-phosphorus (N/P) ratio is known to affect the cell growth of certain marine micro-algae. The nitrogen and phosphorus preference varies between marine microalgae $[38,39]$. The N/P ratio can also be used to predict blooms of algal and their risk. High nitrogen and phosphorus levels are well known to be closely related with harmful algae blooms (HABs) [40]. Depending upon the environmental conditions, the optimal ratios of N/P vary from 8.2 to 45 [41,42]. Diatoms prefer an elevated N/P ratio [43]. Phaeodactylum tricornutum assimilates a ratio of 15:1 of N/P, although that ratio is variable when one of these nutrients is reduced [44]. N/P ratios > 30 indicated phosphorus limitation, whereas ratios $<30$ indicated nitrogen limitation [44].

\section{Response of silicon on diatoms}

Silicon ( $\mathrm{Si}$ ) is one of the most crucial components for the growth of diatoms and is essential to the development, with continued synthesis, of the frustule, a silicon shell. Many candidate proteins, usually involved in diatom $\mathrm{Si}$ metabolism, have been used since late for gene manipulation methods and transcriptomic technology $[45,46]$. Such analyses have expanded our knowledge and methods of the Si response genomic methods and revealed the nature of DA biosilicification's molecular base. Quantitative iTRAQ-based proteomic system for revealing the world metabolic Si-response to Si re-supply or replenishment is present in the Thalassiosira pseudonana diatom model [47]. Approximately $16 \%$ of 
proteins were identified, of which 165 were differentially expressed proteins (DEPs), as Thalassiosira pseudonana genome. In the general silicon transport, cell wall formation and cell cycle growth, DEPs play a role in the number of biochemical processes. Studies like this not only test new protein normally involved in Si reactions. In addition, the intracellular metabolic studies associated with Si response also provide an important insight [48]. It brings new molecular views of what is known about synthesis of cellular walls and progressive cell cycles in diatoms. In addition to the broad information on how the organism responds to silicon resupply and cell cycle growth, the proteomic profiles of the synchronised $T$. pseudonana cultures provide us with small-scale patterns of response for certain proteins.

\section{Proteomic examines on stress responses in diatoms}

While only a very large number of proteomic studies have been performed on diatoms, the data acquired has encouraged a better understanding of the biochemical processes which contribute to their environmental success. The current status of proteomics research on diatomic stress responses, new advances and applications are being explored for examining post-translation protein changes in diatoms. Diatom communities have developed a sophisticated advanced mechanism to detect and adapt to different biotic and abiotic stress factors appropriately. A number of signaling pathways in plants and animals were forecast or checked for diatoms. A process known to promote important adaptations in the physiological and lifecycle of vertebrates has also been investigated and proved essential for diatom growth and metabolism [34]. While significant progress has been made in demonstrating diatom adaptation mechanisms, it is important to study the biochemical processes that contribute to their ecological success and the mechanisms which comprise their multi-faceted responses to various system stresses.

\section{Role of heavy metals in biofuel production from diatom}

Diatom oil production is expected to be 7 to $200 \times$ per hectare compared to oilseed crops. Diatoms play an important role in earth's ecological equilibrium because of their capacity to fix carbon dioxide and are responsible for $\sim 20-25 \%$ of the world net primary production. When the silica shell is discounted, the dry weight of oil per dry weight of the cell may exceed that of any other organism. Geologists suggest that fossil diatoms could be the source of much of the world's crude oil [49]. Diatoms include species which are able to survive in diverse conditions, including high temperature. It has been reported that when diatoms are put under stress conditions (high heavy metal (( $\mathrm{Pb}$ and $\mathrm{Se})$ ) [50], low nutrients, high temperature, low silica, high or low light, etc.) the concentration of oil increases. This could be attributed to the transfer of the lipid metabolism from the intracellular membrane biosynthesis to the storage of lipids. Genetic transformation of diatoms or selective breeding might someday further increase oil production under broader conditions, all diatoms tested by researchers produced oil, but the visible oil content seemed to be maximized in Diadesmis confervacea, which was proved by transesterification. Diatoms with high lipid content and naturally oozing would eliminate the expensive step in energy production of extracting oil out of the diatoms. D. confervacea proved to have both high lipid content and natural, spontaneous secretion of its oil. D. confervacea had the highest lipid content (fatty acid methyl esters (FAME)) about $14.6 \%$ as compared to Nitzschia sp. $5 \%$ [6]. Diatoms are regarded as the reserve food material for the preparation of lipid bodies. In the Gomphonema pseudoaugur diatom species Saraswati dham, Haryana, India which was found to be enriched by heavy metals, higher lipid bodies, both in number and in quantity, had observed [50]. Lipid bodies are more common in terms of nutrient stress, but the state is unclear under heavy metal stress. In contrast to the treatments in laboratory studies the diatom Haslea ostrearia appeared to have higher lipid contents under $\mathrm{Cu}$ stress [51,52] reported induction of lipid bodies identified under $\mathrm{Cu}$ and $\mathrm{Zn}$ stress in the cultivated population of the phytoplankton under laboratory conditions. The marine diatom Asterionella glacialis found lower fatty acid and sterol in $\mathrm{Hg}$ and $\mathrm{Cd}$ stress [50].

\section{Conclusions}

Diatoms are ubiquitous algae present all over the world. Biosilicated cell membrane of diatom makes them different from other microbes. Along with this feature, they show huge variation in in their own community itself just due to the varying size, shape, opacity and is considered a remarkable feature of diatom. Diatoms are widely studied all over the world to show the physical and synthetic state of fluvial biological systems. They are used for biomonitoring purposes for taxonomic and morphological properties of ecosystems, community and human disturbances. The development of diatoms depends on a number of environmental factors, including metal supply. The cells have a strong fitness and develop at 
their maximum growth rates at the moment in which micronutrients are present in a sufficient amount. Many times, the optimum amount of metal in the cell environment is disrupted and 1 or more elements are starving or excessive in cells. The abundance of metals interferes with biochemical and cell processes, which cause a dysfunction that lowers growth and can eventually lead to cell death. Morphological variations in diatoms have been completely examined under various kinds of ecological and anthropogenic disturbances. Diatoms store energy as important carbohydrate chrysolaminarin or distinctive lipid bodies. Many diatoms are appropriate for lipid development up to $70 \%$ of their body volume and are investigated for biofuel as a hotspot. Naturally, diatoms bloom under varying nutrient conditions which mean the maximum growth rate at the highest density and are ideal for a biofuel system.

\section{Acknowledgement}

Authors are thankful to Lovely Professional University for providing necessary facilities for the research study.

\section{References}

[1] FE Round, RM Crawford and DG Mann. Diatoms: Biology and morphology of the genera. Cambridge University Press, Cambridge, England, 2007.

[2] MD Guiry. How many species of algae are there? J. Phycol. 2012; 48, 1057-63.

[3] T Whittington. Biodiesel production and use by farmers: Is it worth considering? Department of Agriculture and Food, Government of Western Australia, Kensington, Western Australia, 2006.

[4] O Sayanova, V Mimouni, L Ulmann, A Morant-Manceau, V Pasquet, B Schoefs and JA Napier. Modulation of lipid biosynthesis by stress in diatoms. Phil. Trans. Roy. Soc. B 2017; 372, 20160407.

[5] R Radakovits, RE Jinkerson, A Darzins and MC Posewitz. Genetic engineering of algae for enhanced biofuel production. Eukaryot. Cell 2010; 9, 486-501.

[6] V Vinayak, R Gordon, S Gautam and A Rai. Discovery of a diatom that oozes oil. Adv. Sci. Lett. 2014; 20, 1256-67.

[7] S Gautam, M Kashyap, S Gupta, V Kumar, B Schoefs, R Gordon, C Jeffryes, KB Joshi and V Vinayak. Metabolic engineering of tio 2 nanoparticles in nitzschia palea to form diatom nanotubes: An ingredient for solar cells to produce electricity and biofuel. RSC Adv. 2016; 6, 97276-84.

[8] A Cattaneo, Y Couillard, S Wunsam and M Courcelles. Diatom taxonomic and morphological changes as indicators of metal pollution and recovery in Lac Dufault (Québec, Canada). J. Paleolimnol. 2004; 32, 163-75.

[9] C Zurzolo and C Bowler. Exploring bioinorganic pattern formation in diatoms. A story of polarized trafficking. Plant Physiol. 2001; 127, 1339-45.

[10] JD Macdonald. I. - On the structure of the diatomaceous frustule, and its genetic cycle. Ann. Mag. Nat. Hist. 1869; 3, 1-8.

[11] E Pfitzer. Über den bau und die zellteilung der diatomeen. Botanische Zeitung 1869; 27, 774-6.

[12] SR Laney, RJ Olson and HM Sosik. Diatoms favor their younger daughters. Limnol. Oceanogr. 2012; 57, 1572-8.

[13] N Kröger and N Poulsen. Diatoms - from cell wall biogenesis to nanotechnology. Annu. Rev. Genet. 2008; 42, 83-107.

[14] LG Frigeri, TR Radabaugh, PA Haynes and M Hildebrand. Identification of proteins from a cell wall fraction of the diatom Thalassiosira pseudonana: Insights into silica structure formation. Mol. Cell. Proteom. 2006; 5, 182-93.

[15] N Poulsen, M Sumper and N Kröger. Biosilica formation in diatoms: Characterization of native silaffin-2 and its role in silica morphogenesis. Proc. Natl. Acad. Sci. Unit States Am. 2003; 100, 12075-80.

[16] SG Lynn, SS Kilham, DA Kreeger and SJ Interlandi. Effect of nutrient availability on the biochemical and elemental stoichiometry in the freshwater diatom Stephanodiscus minutulus (Bacillariophyceae). J. Psychol. 2000; 36, 510-22.

[17] SB Baines, BS Twining, S Vogt, WM Balch, NS Fisher and DM Nelson. Elemental composition of equatorial Pacific diatoms exposed to additions of silicic acid and iron. Deep Sea. Res. II Topical Stud. Oceanogr. 2011; 58, 512-23.

[18] TY Ho, A Quigg, ZV Finkel, AJ Milligan, K Wyman, PG Falkowski and FM Morel. The elemental composition of some marine phytoplankton. J. Psychol. 2003; 39, 1145-59. 
[19] C Tantanasarit, AJ Englande and S Babel. Nitrogen, phosphorus and silicon uptake kinetics by marine diatom chaetoceros calcitrans under high nutrient concentrations. J. Exp. Mar. Biol. Ecol. 2013; 446, 67-75.

[20] LC Gilpin, K Davidson and E Roberts. The influence of changes in nitrogen: Silicon ratios on diatom growth dynamics. J. Sea Res. 2004; 51, 21-35.

[21] KJ Waldron, JC Rutherford, D Ford and NJ Robinson. Metalloproteins and metal sensing. Nature 2009; 460, 823-30.

[22] EV Armbrust. The life of diatoms in the world's oceans. Nature 2009; 459, 185-92.

[23] S Masmoudi, N Nguyen-Deroche, A Caruso, H Ayadi, A Morant-Manceau and G Tremblin. Cadmium, copper, sodium and zinc effects on diatoms: From heaven to hell - a review. Cryptogam. Algol. 2013; 34, 185-225.

[24] R Scharek, MAV Leeuwe and HJD Baar. Responses of southern ocean phytoplankton to the addition of trace metals. Deep Sea. Res. II Topical Stud. Oceanogr. 1997; 44, 209-27.

[25] N Corcoll, B Bonet, S Morin, A Tlili, M Leira and H Guasch. The effect of metals on photosynthesis processes and diatom metrics of biofilm from a metal-contaminated river: A translocation experiment. Ecol. Indicat. 2012; 18, 620-31.

[26] G Sarthou, KR Timmermans, S Blain and P Tréguer. Growth physiology and fate of diatoms in the ocean: A review. J. Sea Res. 2005; 53, 25-42.

[27] Á Cid, E Torres, C Herrero and J Abalde. Disorders provoked by copper in the marine diatom Phaeodactylum tricornutum in short-time exposure asays. Cah. Biol. Mar. 1997; 38, 201-6.

[28] L Alipanah, J Rohloff, P Winge, AM Bones and T Brembu. Whole-cell response to nitrogen deprivation in the diatom Phaeodactylum tricornutum. J. Exp. Bot. 2015; 66, 6281-96.

[29] MJ Behrenfeld, KH Halsey and AJ Milligan. Evolved physiological responses of phytoplankton to their integrated growth environment. Philos. Trans. R. Soc. Lond. B Biol. Sci. 2008; 363, 2687-703.

[30] NL Hockin, T Mock, F Mulholland, S Kopriva and G Malin. The response of diatom central carbon metabolism to nitrogen starvation is different from that of green algae and higher plants. Plant Physiol. 2012; 158, 299-312.

[31] P Claquin, V Martin-Jézéquel, JC Kromkamp, MJ Veldhuis and GW Kraay. Uncoupling of silicon compared with carbon and nitrogen metabolisms and the role of the cell cycle in continuous cultures of Thalassiosira pseudonana (Bacillariophyceae) under light, nitrogen, and phosphorus control. $J$. Phycol. 2002; 38, 922-30.

[32] AE Allen, CL Dupont, M Oborník, A Horák, A Nunes-Nesi, JP McCrow, H Zheng, DA Johnson, H $\mathrm{Hu}$ and AR Fernie. Evolution and metabolic significance of the urea cycle in photosynthetic diatoms. Nature 2011; 473, 203-7.

[33] M Palmucci, S Ratti, M Giordano. Ecological and evolutionary implications of carbon allocation in marine phytoplankton as a function of nitrogen availability: A fourier transform infrared spectroscopy approach. J. Phycol. 2011; 47, 313-23.

[34] Y Wang, J Fang, SS Leonard and KMK Rao. Cadmium inhibits the electron transfer chain and induces reactive oxygen species. Free Radic. Biol. Med. 2004; 36, 1434-43.

[35] CB Field, MJ Behrenfeld, JT Randerson and P Falkowski. Primary production of the biosphere: Integrating terrestrial and oceanic components. Science 1998; 281, 237-40.

[36] Q KaiXian and MA Borowitzka. Light and nitrogen deficiency effects on the growth and composition of Phaeodactylum tricornutum. Appl. Biochem. Biotechnol. 1993; 38, 93-103.

[37] ST Dyhrman, BD Jenkins, TA Rynearson, MA Saito, ML Mercier, H Alexander, LP Whitney, A Drzewianowski, VV Bulygin and EM Bertrand. The transcriptome and proteome of the diatom Thalassiosira pseudonana reveal a diverse phosphorus stress response. PloS one 2012; 7, e33768.

[38] DR Clark, KJ Flynn and NJ Owens. The large capacity for dark nitrate-assimilation in diatoms may overcome nitrate limitation of growth. New Phytol. 2002; 155, 101-8.

[39] KJ Flynn. How critical is the critical N:P ratio? J. Phycol. 2002; 38, 961-70.

[40] TJ Smayda. Complexity in the eutrophication-harmful algal bloom relationship, with comment on the importance of grazing. Harmful Algae 2008; 8, 140-51.

[41] CA Klausmeier, E Litchman, T Daufresne and S Levin. Phytoplankton stoichiometry. Ecol. Res. $2008 ; 23,479-85$.

[42] CA Klausmeier, E Litchman, $\mathrm{T}$ Daufresne and SA Levin. Optimal nitrogen-to-phosphorus stoichiometry of phytoplankton. Nature 2004; 429, 171-4.

[43] ZX Hu, N Xu, AF Li and SS Duan. Effects of different N:P ratios on the growth of Pseudo-nitzschia pungens, Prorocentrum donghaiense and Phaeocystis globosa. Acta Hydrobiol. Sin. 2008; 32, 4827. 
[44] Q Zhang and G Hu. Effect of nitrogen to phosphorus ratios on cell proliferation in marine micro algae. Chin. J. Oceanol. Limnol. 2011; 29, 739-45.

[45] ST Dyhrman, JW Ammerman and BAV Mooy. Microbes and the marine phosphorus cycle. Oceanography 2007; 20, 110-6.

[46] RP Shrestha, B Tesson, T Norden-Krichmar, S Federowicz, M Hildebrand and AE Allen. Whole transcriptome analysis of the silicon response of the diatom Thalassiosira pseudonana. BMC Genom. 2012; 13, 499.

[47] MA Brzezinski. Mining the diatom genome for the mechanism of biosilicification. Proc. Natl. Acad. Sci. Unit States Am. 2008; 105, 1391-2.

[48] C Du, JR Liang, DD Chen, B Xu, WH. Zhuo, YH. Gao, CP Chen, C Bowler and W Zhang. iTRAQbased proteomic analysis of the metabolism mechanism associated with silicon response in the marine diatom Thalassiosira pseudonana. J. Proteome Res. 2014; 13, 720-34.

[49] R Gordon and J Seckbach. The science of algal fuels: Phycology, geology, biophotonics, genomics and nanotechnology. Springer Science \& Business Media, Heidelberg, Germany, 2012.

[50] S Gautam, LK Pandey, V Vinayak and A Arya. Morphological and physiological alterations in the diatom Gomphonema pseudoaugur due to heavy metal stress. Ecol. Indicat. 2017; 72, 67-76.

[51] L Joux-Arab, B Berthet and JM. Robert. Do toxicity and accumulation of copper change during size reduction in the marine pennate diatom Haslea ostrearia? Mar. Biol. 2000; 136, 323-30.

[52] LK Pandey and EA Bergey. Exploring the status of motility, lipid bodies, deformities and size reduction in periphytic diatom community from chronically metal $(\mathrm{Cu}, \mathrm{Zn})$ polluted waterbodies as a biomonitoring tool. Sci. Total Environ. 2016; 550, 372-81. 